$$
\text { [ cover sheet - EarthArXiv] }
$$

\title{
Barrier islands as coupled human-landscape systems
}

\author{
Dylan E. McNamara ${ }^{1} \&$ Eli D. Lazarus ${ }^{2}$
}

${ }^{1}$ Department of Physics and Physical Oceanography, Center for Marine Science, University of North Carolina, Wilmington, North Carolina, USA; mcnamarad@uncw.edu; Twitter: @drdylanmcnamara

${ }^{2}$ Environmental Dynamics Lab, School of Geography \& Environmental Science, University of Southampton, Southampton, UK; E.D.Lazarus@soton.ac.uk; Twitter: @envidynxlab

Nota bene-

This manuscript is a non-peer-reviewed preprint submitted to Earth ArXiv, provided by the authors as a means to ensure open access to scholarly work on a non-commercial basis.

This version is our initial submission, not the "author's accepted manuscript". The final, peer-reviewed version of this manuscript includes slightly different content.

If you find this work is useful to you, please refer to the published version as:

McNamara D.E., Lazarus E.D. (2018) Barrier Islands as Coupled Human-Landscape Systems. In: Moore L., Murray A. (eds) Barrier Dynamics and Response to Changing Climate. Springer, Cham., 363-383, https://doi.org/10.1007/978-3-319-68086-6 12

Many thanks -

$\mathrm{DM} \& \mathrm{EL}$ 
*** Please note that this is a preprint and not peer-reviewed. This work is provided by the authors as a means to ensure open access to scholarly work on a non-commercial basis.***

\title{
BARRIER ISLANDS AS COUPLED HUMAN-LANDSCAPE SYSTEMS
}

\author{
Dylan E. McNamara ${ }^{1}$ \\ Eli D. Lazarus ${ }^{2}$ \\ ${ }^{1}$ Department of Physics and Physical Oceanography, Center for Marine Science, University \\ of North Carolina, Wilmington, North Carolina, USA \\ ${ }^{2}$ Environmental Dynamics Lab, Geography and Environment Unit, University of \\ Southampton, Southampton, UK
}

There are nearly 300 barrier islands between Maine and Texas, and of these, at least 70 are intensively developed. Mean population density along the U.S. Atlantic and Gulf coasts are the highest in the country. Such concentrated development exists and continues despite the fact that barrier islands are transient landscapes, not only over geologic time scales of millennia but also within human and economic time scales of centuries to decades. Populated barrier islands are inherently vulnerable to natural hazards such as sea-level rise, cumulative erosion, and storm events; this vulnerability drives humans to actively modify barrier geometry and environments. The most common manipulations are beach nourishment, to mitigate shoreline erosion, and increases to dune height or seawall construction to prevent flooding and damage from overwash during storm events. Over time scales of years to decades, hazard-mitigation actions impact natural, spatio-temporal barrier processes such as washover deposition and planform transgression, which in turn affect future efforts to manage, control, or prevent barrier change. Through their maintenance and persistence, interventions against coastal hazards represent a significant dynamical component of developed barrier-island system evolution, such that, within the past century, human actions and natural barrier-island processes have become dynamically coupled. This coupling leads to steady-state barrier island behaviors that are fundamentally new. The only way to understand how developed barrier islands will respond to climate change over decadal time scales is to treat these settings as strongly coupled human-natural systems. Over time scales longer than centuries, human interventions may be coupled only weakly to long-term barrier dynamics. Short of major technological advancements or sweeping decisions to transform these environments into comprehensively geoengineered terrains, high-density development on U.S. barrier islands will likely cease to exist in its current configuration. 
*** Please note that this is a preprint and not peer-reviewed. This work is provided by the authors as a means to ensure open access to scholarly work on a non-commercial basis. $* * *$

\subsection{INTRODUCTION}

For developed barrier islands around the world, hazard and risk are both increasing. Intensifying and often compounded coastal hazards include shoreline erosion, storm flooding, and sea-level rise. Likewise, risk is increasing as a function of population density and infrastructural development in coastal zones worldwide. As a result, coastal environments - and barrier islands, especially - are being transformed by management decisions, hazard-mitigation interventions, and deliberate manipulation of coastal morphology. Mainstream (as opposed to heterodox) economics defines risk as the likelihood of a hazard event - physical change of a given magnitude driven by a natural event or process - multiplied by the value of assets and infrastructure susceptible to damage from that event. (By this definition, in the absence of valued assets, an environment may be subject to hazard without risk.) A recent report by the U.S. National Research Council applies a somewhat broader scope, defining coastal risk "as the potential for coastal hazards, such as storm surge-induced flooding and wave attack, to cause adverse effects on human health and well-being; economic conditions; social, environmental, and cultural resources; infrastructure; and the services provided within a community" (NRC 2014, p. 1). Coastal management and engineering interventions to reduce risk and mitigate hazard impacts often have unintended consequences, including complex feedbacks between human activities and physical coastal change that researchers are just beginning to understand.

Barrier islands comprise approximately $10 \%$ of the world's open-ocean coastline, and more than 400 barrier islands fringe the seaboards of the United States; collectively, they represent $24 \%$ of barrier-island shoreline length worldwide, a quantity more than twice the next 
***Please note that this is a preprint and not peer-reviewed. This work is provided by the authors as a means to ensure open access to scholarly work on a non-commercial basis. $* * *$

highest national total (Mexico; 11\%) (Stutz and Pilkey 2011). There are nearly 300 barrier islands between Maine and Texas, accounting for over 16,800 $\mathrm{km}^{2}\left(\sim 6500 \mathrm{mi}^{2}\right)$ of land area, or $1.5 \%$ of coastal shoreline county area along the Atlantic and Gulf Coasts. Of these, at least 70 are intensively developed. Between 1945-1975, land used for urban development increased by $153 \%$ (over $\sim 500 \mathrm{~km}^{2}$ or $\sim 200 \mathrm{mi}^{2}$ ); in 1975, urban development comprised $14 \%$ of Atlantic and Gulf Coast barrier island land area, when the national average was only 3\% (Dolan 2000). In many states, especially through the Mid-Atlantic, barrier islands host a disproportionate amount of high-value housing stock (Nordstrom 2000).

Moreover, these same places have experienced marked increases in population. According to recent Census data, the mean percent historic population change for coastal shoreline counties in the U.S. (defined as "counties are directly adjacent to the open ocean, major estuaries, and the Great Lakes") increased by 39\% between 1970-2010, but coastal shoreline counties along the U.S. Eastern Seaboard and Gulf Coast saw a 62\% change. (The U.S. mean for all counties was 52\%.) Mean population density in Atlantic and Gulf Coast shoreline counties (556 people $\mathrm{mi}^{-2}$ ) already exceeds the categorical (446 people $\mathrm{mi}^{-2}$ ) and national (105 people $\mathrm{mi}^{-2}$ ) densities. (Note that the U.S. Census calculates density in terms of square miles, by convention.) Of the total number of housing units in the U.S. in 2010, 39\% were in coastal shoreline counties, along with $42 \%$ of all U.S. seasonal homes. Nearly 4 million new housing units appeared in coastal shoreline counties between 2000-2010, representing an 8\% increase overall; seasonal units increased by $18 \%$. At last count, $52 \%$ of U.S. households with an annual household income greater than $\$ 150,000$ were in coastal shoreline counties (NOAA 2013). 
***Please note that this is a preprint and not peer-reviewed. This work is provided by the authors as a means to ensure open access to scholarly work on a non-commercial basis. $* * *$

The inherently transient nature of the barrier island landscape (FitzGerald et al. 2008) makes development on barrier islands inherently vulnerable to natural coastal hazard, and drives humans to actively modify barrier geometry and environments. The most common manipulations are beach nourishment, to mitigate shoreline erosion, and increases to dune height or seawall construction to prevent flooding and damage from overwash during storm events. As human interventions modify the natural environment to make it more accommodating for development, those modifications affect spatio-temporal changes resulting from natural physical processes, which in turn affect subsequent interventions. For example, beach nourishment alters distribution of barrier overwash (and washover) in space and time, barrier height and width, and spatial patterns of change in planform shoreline position. Adjustments to (or prevention of) these barrier processes and traits in turn affect management and engineering decisions regarding future nourishment projects. The ubiquity, maintenance, and persistence of beach nourishment, dune construction, cliff stabilization, and seawalls, jetties, and other structures mean that interventions and modifications now function as intrinsic morphodynamic components of the developed barrier system - and thus control how developed barrier islands evolve as landforms.

Over intermediate time scales of years to decades, human actions and barrier island processes are therefore dynamically coupled. Werner and McNamara (2007, p. 399) describe the constituent parts of a human-landscape system in which dynamic coupling is particularly strong: 
*** Please note that this is a preprint and not peer-reviewed. This work is provided by the authors as a means to ensure open access to scholarly work on a non-commercial basis. $* * *$

"...human-landscape coupling should be strongest where fluvial, oceanic or atmospheric processes render significant stretches of human-occupied land vulnerable to large changes and damage, and where market processes assign value to the land and drive measures to protect it from damage. These processes typically operate over the (human) medium scale of perhaps many years to decades over which landscapes become vulnerable to change and over which markets drive investment in structures, evaluate profits from those investments and respond to changes in conditions."

On barrier islands, coupling leads to dynamical states into which the developed coastal system may evolve, termed 'attractors', that represent a subset of its possible configurations, such as states characterized by high-density infrastructure, high property value, and significant investment in mitigation practices. Present attractors for developed barriers may also include chaotic evolution of beach width (Lazarus et al. 2011), 'sucker' and 'free-rider' dynamics among neighboring coastal towns (Williams et al. 2013), and complex spatial connections between locations separated by long distances within regional-scale littoral cells (Slott et al. 2008; Slott et al. 2010; McNamara et al. 2011; Ells and Murray 2012; Murray et al. 2013).

As external forcing such as sea-level rise and coastal erosion rates increase, dynamical attractors for barrier islands are likely to become unstable. For example, recent work suggests that economic markets may anticipate the increasingly precarious nature of barrierisland real estate as sea level rises, and perhaps drive divestment from barrier-island property 
***Please note that this is a preprint and not peer-reviewed. This work is provided by the authors as a means to ensure open access to scholarly work on a non-commercial basis. $* * *$

(McNamara and Keeler 2013). If divestment from developed barrier islands turns into abandonment, it is not clear what the future of these environments will be. Ancient examples of coastal development, abandonment, and reoccupation are at best distant analogs for modern society (Dunning et al. 2012; Turner and Sabloff 2012). Conceptual frameworks for spatio-temporal patterns in tourist-driven economies still struggle to resolve more than one iteration of a boom-bust cycle (Butler 2006). Some work has suggested that after abandonment, the evolution of 'fresh', less precarious (albeit temporarily) natural barrierisland sites entices renewed development, such that development pressures shift across and within a given barrier system in space and time (McNamara and Werner 2008a). This posited boom-and-bust attractor emerges over long time scales, making it difficult to constrain (McNamara and Werner 2008b). However, its dynamical demonstration new avenues for less reactionary and more holistic coastal management perspectives for barrier systems, and raises questions about whether and how society may adapt to coastal change, whether through abandonment or reinforcement of economic drivers to continue intensifying coastal development.

Traditional approaches to understanding decadal- to centennial-scale evolution of coastal systems have either treated human activity as a perturbation to physical dynamics, or treated physical change as a perturbation to human activity. However, both are unidirectional treatments of cause and effect, and cannot address the feedback-driven, coupled dynamics of change along developed coastlines (Nordstrom 1994, 2000; Lazarus et al. 2015). In this chapter, we elaborate on beach nourishment as a specific linking mechanism in the coupled dynamics of developed barrier islands, and on how this coupled system evolves to current 
***Please note that this is a preprint and not peer-reviewed. This work is provided by the authors as a means to ensure open access to scholarly work on a non-commercial basis. $* * *$

configurations along dense coastlines with unanticipated emergent behaviors. We also explore some controlling factors on the timing of destabilization of coupled coastal systems as sea level rises and erosion increases. Finally, we summarize work that evolves coupled coastal systems over longer time scales, and discuss what potentially 'uncoupled' developed coastal systems might mean for future coastal vulnerability to extreme events.

\subsection{BEACH NOURISHMENT AND COUPLED COASTAL DYNAMICS}

Figure 12.1 illustrates beach nourishment as a coupled human-landscape system (Werner and McNamara 2007). Natural spatial and temporal patterns of shoreline erosion and accretion are a function of net cross-shore and alongshore sediment flux, driven by storm impacts, waves, and other physical transport processes. With coastal development comes the introduction of economic value: beach width becomes a source of natural capital, and proximity to that source of capital affects the values and prices of other assets, from realestate to commercial businesses (Smith et al. 2009). A wide beach is more valuable to a coastal town, both directly and indirectly, than a narrow one. However, natural processes of shoreline change (i.e., coastal hazards) inevitably impinge upon that development, spurring investment in coastal defense and hazard mitigation (e.g., beach nourishment, dune reconstruction). So-called "soft-engineering" strategies like beach nourishment, which typically involves importing sand from a source outside the immediate littoral system and depositing it on a reach of eroding shoreline, tend to be preferable to "hard-engineering" options like seawalls because, relative to the latter, the former sustains the natural capital provided by a consistently wide beach (Pilkey and Wright 1988). Paradoxically, investment in coastal defense then encourages further investment in development and infrastructure 
*** Please note that this is a preprint and not peer-reviewed. This work is provided by the authors as a means to ensure open access to scholarly work on a non-commercial basis. $* * *$

(Nordstrom 1994; Mileti 1999; Bagstad et al. 2007; Werner and McNamara 2007; Smith

2013). Natural physical impacts on the developed coastal zone (e.g., persistent erosion) may

last or intensify over several years to decades, requiring repeated mitigation cycles. For

example, the first reported beach-nourishment project on Wrightsville Beach, near

Wilmington, North Carolina, was in 1939, and the beach has been reworked several times a

decade since the 1980s; likewise, Virginia Beach, Virginia, has undergone several

nourishment episodes per decade since the 1950s (PSDS, 2015).

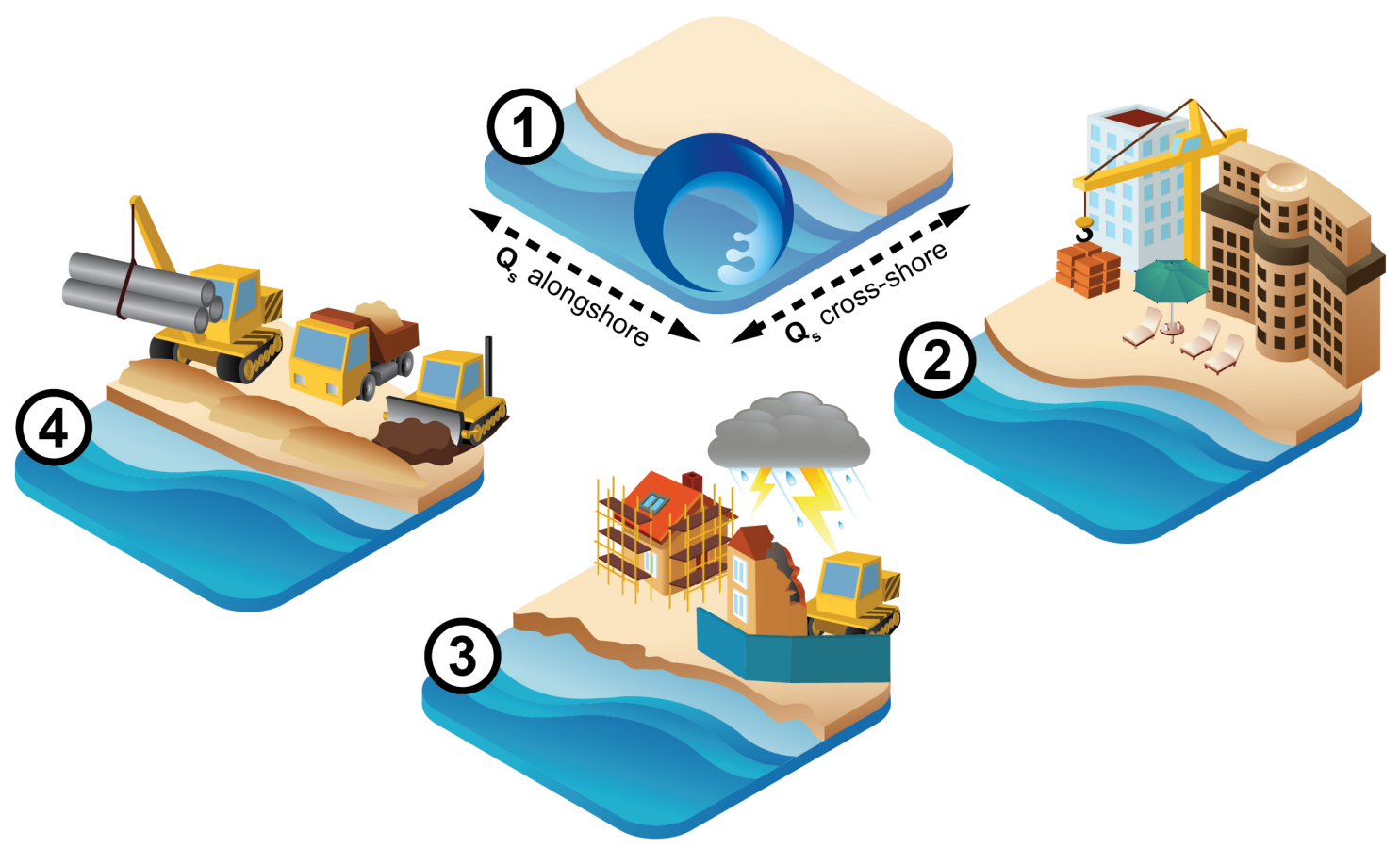

Fig. 12.1 Schematic of a developed barrier coastline as a coupled human-landscape system. (1) Natural processes of sediment transport $\left(Q_{s}\right)$ drive physical coastal changes in space and time; (2) development capitalizes on economically viable coastal real-estate; (3) chronic or event-driven natural hazards damage coastal development and infrastructure, prompting (4) interventions to mitigate or prevent damage in the future. Such interventions modify the physical landscape, altering sediment fluxes in (1), pushing the cycle to iterate. Reprinted with permission from Elsevier from Lazarus et al (2015), An evolving research agenda for human-coastal systems. Geomorphology: dx.doi.org/10.1016/j.geomorph.2015.07.043 
***Please note that this is a preprint and not peer-reviewed. This work is provided by the authors as a means to ensure open access to scholarly work on a non-commercial basis. $* * *$

As these interventions modify the natural condition of the coastline, and as those changes in turn inform subsequent interventions, the reciprocal feedbacks inherent in beach nourishment as a mitigation strategy mean that an artificially nourished coastal zone functions as a fundamentally coupled human-landscape system. Although beach nourishment is a common mitigation strategy that engineers (Dean and Dalrymple 2004), geomorphologists (Nordstrom 1994, 2000), and economists (Smith et al. 2009;

Gopalakrishnan et al. 2011; Hoagland et al. 2012; Jin et al. 2013) have studied in depth, dynamical insight into how persistent nourishment affects economic value of coastal assets and alters coastal response to changes in natural forcing (e.g., storminess, wave climate, sealevel rise) is only beginning to come into focus.

\subsubsection{Modelling the coupled economic-physical system}

Recent work has applied control theory, a perspective that addresses how the behaviors of dynamical systems change as a function of external inputs and internal feedbacks, to explore conditions in which beach nourishment cycles are economically optimal (Smith et al. 2009). This borrows from forestry (Hartman 1976), where tree growth rate, timber value, and fixed costs associated with harvesting yield a time interval between sequential harvests that optimizes the net benefits of the timber stock - that is, the money the timber earns at market minus the fixed costs. Mapped onto beach nourishment, this conceptual framework suggests that erosion rate, the economic value associated with beach width, and the fixed costs of a nourishment project likewise yield a time interval between nourishment episodes that optimizes the net benefits (earnings minus costs) that a coastal town receives. If the town nourishes too frequently, cumulative fixed costs (e.g., permitting, sand acquisition, dredging 
***Please note that this is a preprint and not peer-reviewed. This work is provided by the authors as a means to ensure open access to scholarly work on a non-commercial basis. $* * *$

and earth-moving equipment, labor) exceed the value the beach earns back over the same time period. Oppositely, waiting too long between nourishment episodes means the town loses the revenue it would have earned from a wider beach.

Nourishing at intervals that optimize net economic benefits can be viewed as an emergent state - an attractor in the developed barrier coastline system - that arises once faster-scale market dynamics begin steering nourishment episodes to minimize non-optimal returns. Although the optimization approach does not explicitly simulate all of the dynamics that drive the coastline into its emergent configuration, exploring how this particular attractor, characterized by optimized utility, changes with external conditions reveals insight into its functional dependence on environmental forcing. Analytical work on the emergent dynamics of optimal states has raised some fraught implications, even in these deliberately simplified coastal systems.

One implication is the potential for a runaway feedback of nourishment frequency increasing with nourishment cost (Smith et al. 2009), catalyzing a kind of arms race among neighboring towns for access to beach nourishment material and infrastructure. Indeed, the cost of nourishment, indexed as the price of sand per unit volume, has been increasing over recent decades, as has the volume of sand used for beach nourishment and the number of nourishment episodes (Trembanis et al. 1999; Valverde et al. 1999; PSDS 2015). Another implication is the spatial effect of disparities in property values among series of towns alongshore. The same feedback, in which nourishment frequency increasing with nourishment cost, gives rise to inequity in the efficacy of coastal towns with differing 
***Please note that this is a preprint and not peer-reviewed. This work is provided by the authors as a means to ensure open access to scholarly work on a non-commercial basis. $* * *$

property values to prevent erosion from rising sea level (McNamara et al. 2011): towns with lower property values will likely lose the nourishment arms race to wealthier towns elsewhere, further diminishing property values where they are already low and increasing them where they are already high. A third implication is that the relative contributions of physical, economic, and policy factors to coastal property value could open pathways to potentially rapid property value collapse, whereby the removal of extant government subsidies that reduce effective beach nourishment costs for coastal towns could undercut property values by as much as 60\% (McNamara et al. 2015).

A similiar control-theory approach also has been extended to numerical models coupling agent-based decision-making to large-scale coastline behavior (Lazarus et al. 2011; Jin et al. 2013; Williams et al. 2013). This work explores the how complex shoreline behavior - spatial behaviors beyond the analytically tractable treatment of shoreline evolution - alters the emergent, optimized coastal-economic state. In one set of simulations, a string of towns alongshore share the same initial beach conditions and property values but manager agents take nourishment decisions independently of each other. The model shows spatially myopic nourishment ultimately destabilizing long-term coastline behavior. Despite individual manager agents following nourishment schedules that they determine are economically optimal, the system overall transitions into chaotic evolution (Lazarus et al., 2011). Destabilization occurs as gradients in alongshore sediment transport increase erosion rates in some places and slow them in others, in patterns that change as different towns nourish out of sync. The introduction of such variability in the beach-width data that a given manager agent must interpret means that agents are constantly recalculating the nourishment interval 
***Please note that this is a preprint and not peer-reviewed. This work is provided by the authors as a means to ensure open access to scholarly work on a non-commercial basis. $* * *$

that yields an economic optimum. Collectively, the entire model developed coastline departs from its economic optimum and cannot recover it. Spatially myopic nourishment is characteristic of most U.S East Coast nourishment programs (Smith et al. 2009; Lazarus et al. 2011).

Subsequent simulations for further complex coastline configurations (Murray and Ashton 2013), such as the cuspate planform of the North Carolina coast, have shown that not only does modeled erosion mitigation result in spatial patterns of shoreline erosion and accretion that differ significantly from the spatial patterns that would otherwise occur under natural conditions, but also that sites of sustained nourishment intervention are not a simple reflection of background erosion patterns (Slott et al. 2010; Ells and Murray 2012; Hapke et al. 2013; Williams et al. 2013). Shifts in spatial patterns of erosion and accretion results in a chronic system of 'suckers', who experience exacerbated erosion rates and compensate with more frequent nourishment, and 'free-riders', who benefit from extra sand (and lower erosion rates, if not shoreline accretion) supplied by their updrift neighbors. When linked to property value, these persistent differences in beach width can drive disparities in town property values alongshore that eventually span orders of magnitude (Williams et al. 2013).

\subsubsection{Developed coastlines and common-pool resources}

The 'suckers' and 'free-riders' problem brings beach nourishment into a broader discourse regarding the social and natural dynamics of common-pool resource systems (Lazarus et al. 2015). Common-pool resources are characterized by being openly accessible to users, who must find ways to share the resource, or not; different user groups may use the same 
***Please note that this is a preprint and not peer-reviewed. This work is provided by the authors as a means to ensure open access to scholarly work on a non-commercial basis. $* * *$

resource in different ways. Common-pool resources range from agricultural land and fishing grounds to the Earth's atmosphere. In Hardin's (1968) "tragedy of the commons" narrative, local farmers pasture their cows on the town common; because each farmer always has the same incentive to pasture one more cow, the common soon becomes crowded with cows, who graze it bare, and the arrangement of open access to a shared resource ultimately fails. Other resource economists have generated a huge body of counter-examples (Ostrom et al. 1999; Dietz et al. 2003) in which social institutions, often self-organized, prevent resource collapse and correct inequities among users. But common-pool resources in which the resource flows in a particular direction or otherwise moves in space and time while user groups remain spatially fixed constitute "asymmetrical commons" (Ostrom and Gardner 1993), and represent a particular - and particularly difficult - kind of dynamical problem.

For example, consider an irrigation system (Freeman 1990). Water flows downstream from an upstream source, with farmers distributed along its route. Too much water use or leaky infrastructure upstream limits the quantity of water available to farmers downstream. If farmers upstream fix the leaks in their irrigation works, farmers downstream benefit even if their own irrigation works are in disrepair. The unidirectional movement of the resource (from upstream down) means that, in the first case of imbalance, farmers upstream lack an incentive to account for farmers downstream, and in the second case, farmers downstream have every incentive to free-ride on infrastructural upkeep by farmers upstream (who become the suckers in this hypothetical system). 
***Please note that this is a preprint and not peer-reviewed. This work is provided by the authors as a means to ensure open access to scholarly work on a non-commercial basis. $* * *$

On developed coastlines, and developed barrier islands in particular, beach nourishment and hard structures can have both local and nonlocal effects on shoreline change within a common littoral cell in which sand (and, by extension, beach width) is the shared resource (Stone and Kaufman 1988). For coastal segments in which net alongshore sediment flux has a predominant direction, emplacement of sand-trapping hard structures like groynes and jetties affect sand supply immediately downdrift, but by modifying the planform shape of the coastline, they also affect gradients in sediment flux over significant distances (Ells and Murray 2012). These nonlocal effects then play out along the length the littoral cell in the economic decisions individual towns must make regarding subsequent mitigation actions. As shoreline management decisions in one place become an indirect function of similar but uncoordinated actions elsewhere, an emergent attractor results (at least when optimization functions as the primary coupling mechanism between the system's physical and economic components) (Lazarus et al. 2011). This attractor is ultimately characterized by unequal access to nourishment sand as a resource, as towns with high property values can afford mitigation when less wealthy towns cannot, and thus gain significant advantages in withstanding coastal hazard. Although theoretical, this insight has important implications for policy as it suggests that a more holistic management approach is necessary to avoid rapid depletion of coastal sediment resources and severe economic disparities in defense capacity even across coastal towns within the same region (McNamara et al. 2011; Williams et al. 2013). Likewise, predictions of property-value loss based on scenarios for potential changes to policy regarding nourishment subsidy and insurance coverage suggests a cautionary approach ahead of any hasty changes in coastline mitigation practices (McNamara et al. 2015). 
***Please note that this is a preprint and not peer-reviewed. This work is provided by the authors as a means to ensure open access to scholarly work on a non-commercial basis. $* * *$

\subsection{INUNDATION AND ABANDONMENT: AN ATTRACTOR DISAPPEARS}

Although beach nourishment tempers short-term erosion hazard and dune construction can prevent damage from small and intermediate storm events, neither mitigation action will prevent developed barrier islands from inundation as sea level rises. Given this fate, recent numerical modeling has explored specific controlling factors that influence the timing of when developed barriers, as they are presently configured with high property value, dense infrastructure, and frequent mitigation efforts, will cease to be stable or viable as coupled systems (McNamara and Keeler 2013). The modeling work focuses on the roles that coastal property markets, measured observations of coastal change, and belief among market agents in projections of future climate change all play in altering the long-term behavior of a generic developed barrier system. This use of agent decision-making, which approaches key questions in current discourse on coastal vulnerability and adaptation to climate change (NRC 2014), divides a coastal real-estate market into agents who range from those take climate-change predictions into account and those who do not (Phillips 2012). Given data on historical trends and scientific model predictions about environmental characteristics associated with barrier island and storm behavior (e.g., erosion rates, storm impacts, storm recurrence intervals), individual agents weigh the available information differently to decide how much to pay for a shorefront property and how much to spend on coastal defense. The results show that, relative to agents with little belief in climate-change predictions, informed property owners invest heavily in defensive measures in the short term. However, they abandon coastal real estate when price volatility becomes so significant that they no longer 
***Please note that this is a preprint and not peer-reviewed. This work is provided by the authors as a means to ensure open access to scholarly work on a non-commercial basis. $* * *$

think defensive expenditures worthwhile. Their exit from the market has a striking effect (McNamara and Keeler 2013, p. 561):

"The amount of property damage is larger when model predictions do not inform beliefs, and the magnitude of this difference rises as the rate of SLR [sealevel rise] increases....As non-believers [in projected environmental change] are more likely to own property during periods of high risk, this highlights an important equity issue. Disaster assistance typically represents income transfers from taxpayers as a whole to affected populations..., and the systematic selection of...non-believers into the property market means that broader society is funding repairs for damages that the average citizen would not have suffered."

How private markets anticipate increasing risk and guide adaptive behavior is a key component of policy discussions on coastal adaptation (NRC 2014), especially at the social scale of local residents and community land-use planning processes, and remains a major challenge in future research into the developed-coastline dynamics (Lazarus et al. 2015).

\subsubsection{Modeling the decision to abandon: physical forcing}

To extend this previous work on developed barrier abandonment, here we investigate other factors that may influence when the coastal home-owner agents in the McNamara and Keeler (2013) coupled model choose to abandon coastal property. The model begins with an initial physical barrier-island state similar to barriers found along the North Carolina Outer Banks, USA. As in the original model, agents can buy and sell coastal properties located 
***Please note that this is a preprint and not peer-reviewed. This work is provided by the authors as a means to ensure open access to scholarly work on a non-commercial basis. $* * *$

upon the modeled barrier island. Simulations are run for two sea-level rise scenarios: a 'calm' scenario with rates of sea level rise at $3 \mathrm{~mm} / \mathrm{yr}$, and a 'worst-case' scenario of rates of sea level rise at $10 \mathrm{~mm} / \mathrm{yr}$. (For specific details of all model dynamics, see McNamara and Keeler 2013.)

First, we examine how an increase in mean storm surge magnitude impacts (a) the time that elapses before coastal inhabitants abandon their property, and (b) the total damage that occurs prior to abandonment. Simulations are run at both sea-level-rise rates. Results show that for rates under both the 'calm' and 'worst-case' scenarios, time to abandonment is reduced as storm magnitude increase (Fig. 12.2). The amount of damage that occurs prior to abandonment increases significantly with larger increases in mean storm surge magnitude. However, the amount of damage is not a strong function of the rate of sea-level rise; the cumulative damage that occurs in the lead-up to abandonment, when the barrier is precariously low, constitutes the majority of the total damage suffered, which suggests abandonment is driven by additive damage rather than any single event. 
*** Please note that this is a preprint and not peer-reviewed. This work is provided by the authors as a means to ensure open access to scholarly work on a non-commercial basis. $* * *$
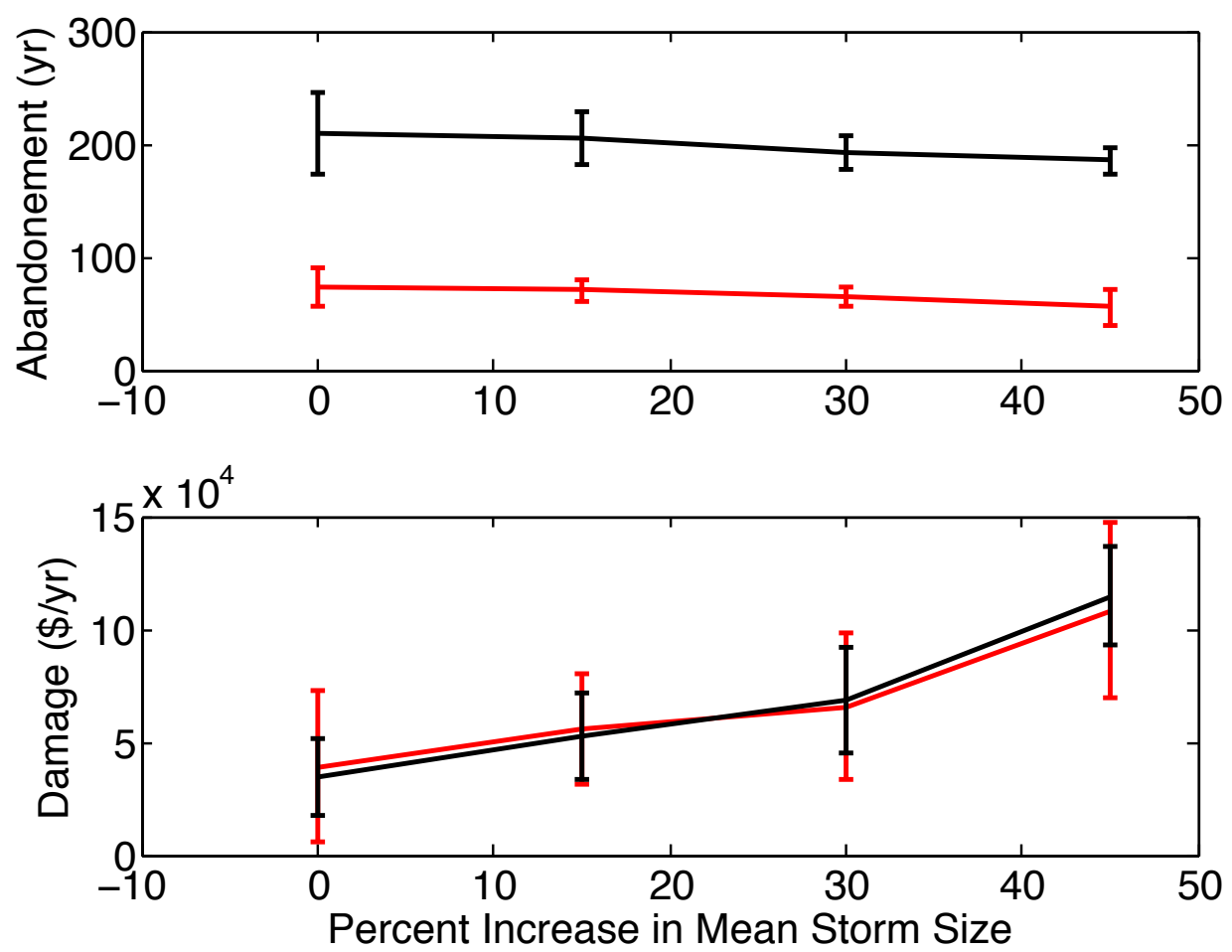

Fig. 12.2 For a hypothetical developed barrier island, elapsed time before abandonment and associated total damage sustained as a function of percent increase in mean storm surge magnitude. Black and red (gray) lines denote 'worst-case' and 'calm' sea-level rise scenarios, respectively.

\subsubsection{Modeling the decision to abandon: policy forcing}

To examine the role that policy plays in abandonment, we introduce a subsidy for beach nourishment costs into the model. Historically, the cost for most beach nourishment projects along the U.S. East Coast is subsidized by the government at a rate of $66 \%$ (NOAA 2006). When simulations are run with the nourishment subsidy ranging from $0-60 \%$ for the low and high rates of sea-level rise, time to abandonment and the amount of damage prior to abandonment both increase as the subsidy is increased (Fig. 12.3). This result again raises issues of equity: given that the nourishment subsidy and emergency repairs in the wake of major storms are funded from taxes paid by national populace, not just local coastal property 
*** Please note that this is a preprint and not peer-reviewed. This work is provided by the authors as a means to ensure open access to scholarly work on a non-commercial basis. $* * *$

owners, tandem increases in both subsidies would likely draw political fire (Pilkey and Dixon 1996).
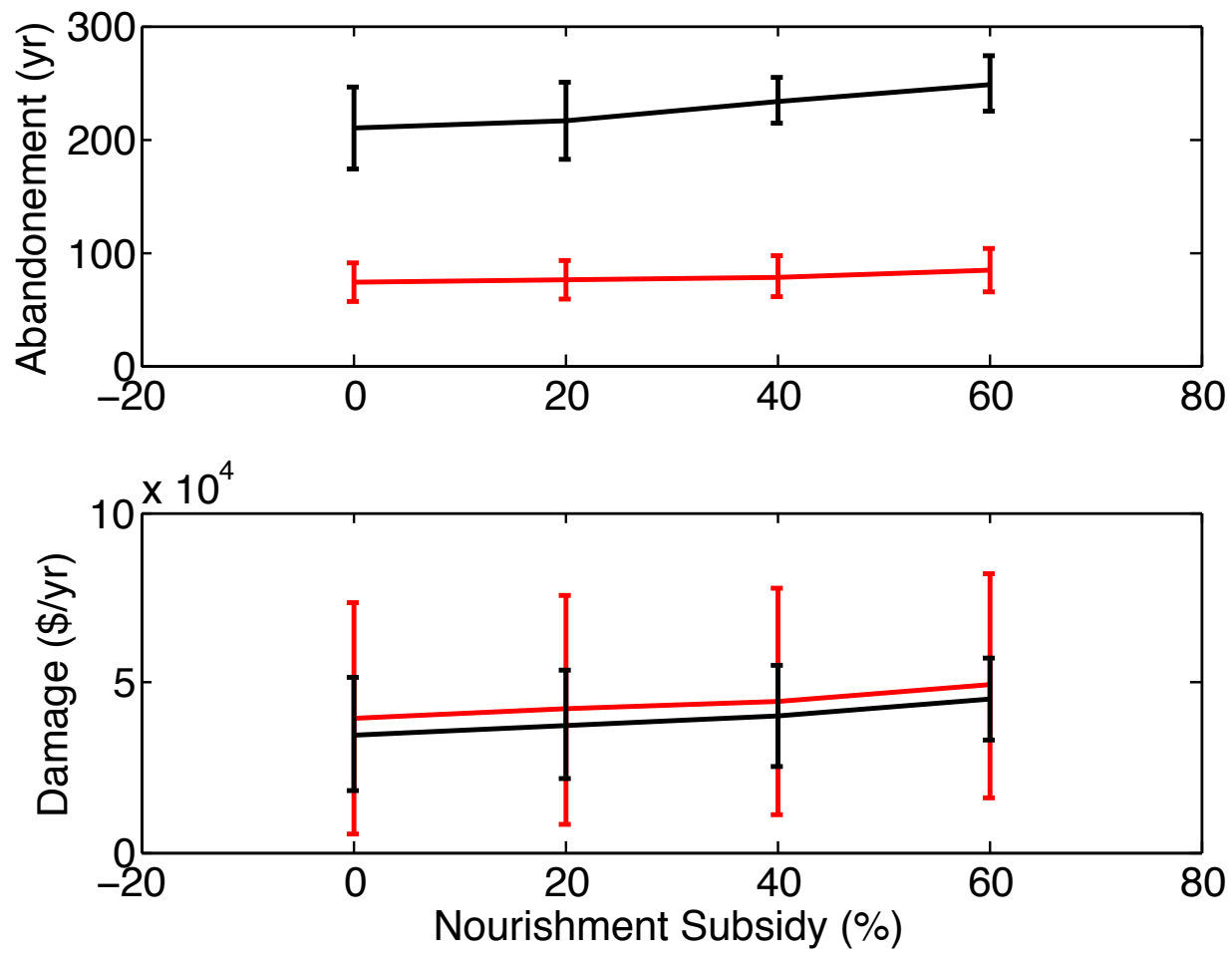

Fig. 12.3 Elapsed time before abandonment and associated total damage sustained as a function of percent increase in federal nourishment subsidy. Black and red (gray) lines denote 'worst-case' and 'calm' sea-level rise scenarios, respectively.

Finally, to examine how individual perceptions of environmental change might impact abandonment, we run simulations in which agents' mean "belief" in forward-looking, "science-based" forecasts is increased. The impact of belief in "science-based" projections is more evident when the rates of sea-level rise are high. In that case, increasing the weight agents give to forecasts of barrier evolution causes both time to abandonment and damage to decrease (Fig. 12.4). This result highlights that when the rate of sea-level rise is high, the ability of agents to adapt rapidly to the prospect of significantly diminished future returns, 
*** Please note that this is a preprint and not peer-reviewed. This work is provided by the authors as a means to ensure open access to scholarly work on a non-commercial basis. $* * *$

rather than simply rely on past observations, can affect the total amount of damage sustained prior to barrier abandonment.
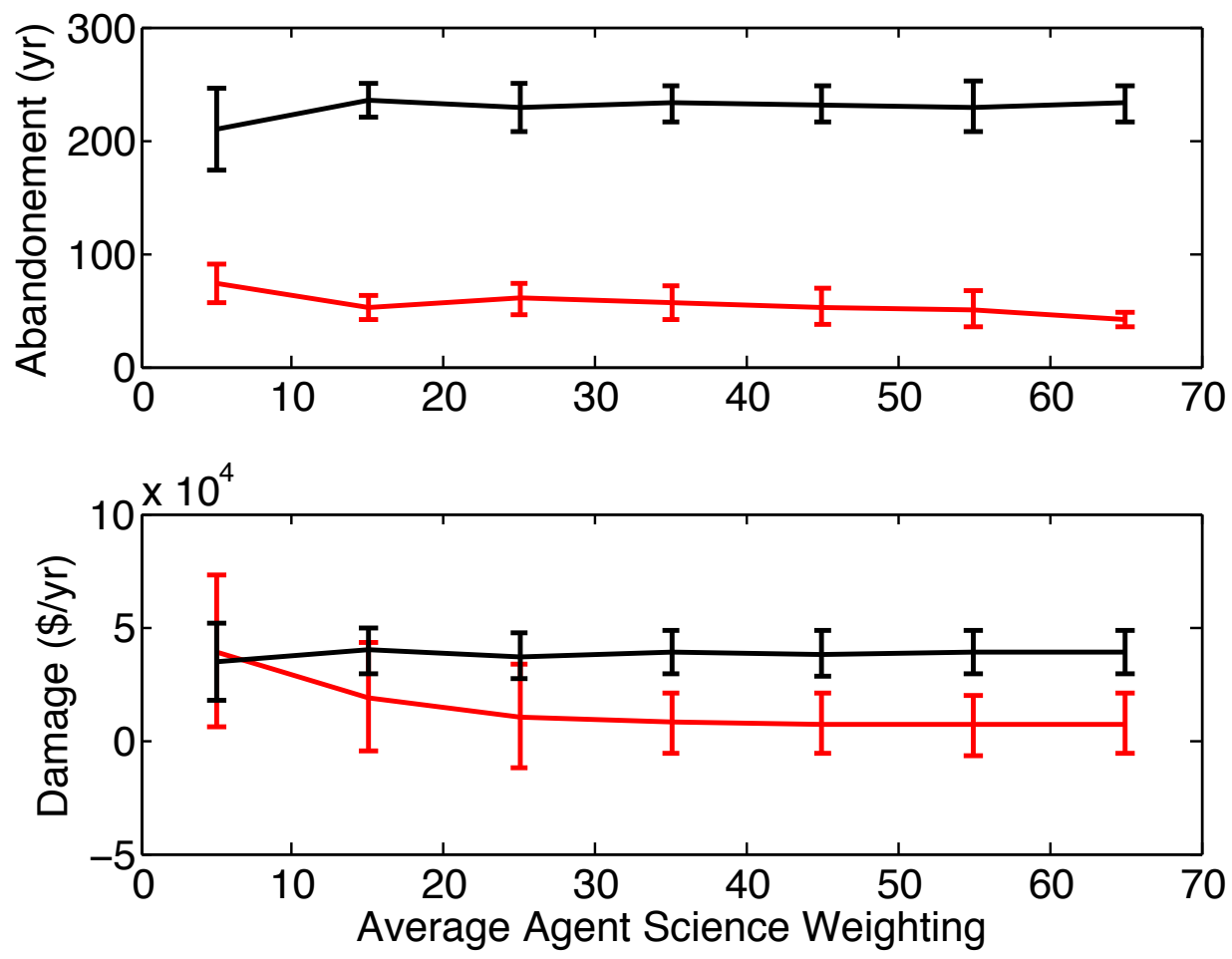

Fig. 12.4. Elapsed time before abandonment and associated total damage sustained as a function of the mean weight a given agent lends to "science-based" forecasts of barrierisland change. Black and red (gray) lines denote 'worst-case' and 'calm' sea-level rise scenarios, respectively.

These extensions of the coupled model by McNamara and Keeler (2013) bring to focus the range of forcing factors that control the timing of systemic instability under conditions representative of developed barriers today. Coastal research typically focuses on sea-level rise rates when discussing the fate of populated barrier islands. Although sea-level rise is certainly an important factor, other physical forcing (storm surge size), policy forcing (rate of nourishment subsidy), and psychological forcing (belief in forward looking models) can play 
***Please note that this is a preprint and not peer-reviewed. This work is provided by the authors as a means to ensure open access to scholarly work on a non-commercial basis. $* * *$

a prominent, if not dominant, role in steering the path toward (or away from) destabilization of the barrier island attractor and subsequent barrier abandonment.

\subsection{BOOM, BUST, REPEAT: AN ATTRACTOR EMERGES}

Modeling the long-term dynamics of developed coastlines and coastal-resort economies over time scales on the order of centuries, rather than decades, reveals a potential emergent behavior - one of boom and bust cycles - that could play out beyond the time when initial abandonment occurs. For example, McNamara and Werner (2008a) coupled a threedimensional numerical model of barrier-island evolution with an agent-based model of tourism development. The basic structure of the model routine is the same as the cycle shown in Fig. 12.1. Natural physical processes (e.g., nearshore bar migration, alongshore sediment transport, dune growth, sea-level rise) rework the barrier island. Meanwhile, heterogeneous economic agents, divided into developers, hotel owners, and tourists, interact in a simulated market for tourism real-estate. A policy agent in each shoreline cell alongshore tracks beach width and decides when to implement beach and dune nourishment; if nourishment will result in a net gain in revenue and property appreciation (relative to no nourishment) after costs, then the nourishment project goes ahead. Because populous locations in the model generate significantly more revenue relative to the cost of a nourishment project, they are more likely to replenish (Valverde et al. 1999). In addition to shoreline erosion from sea-level rise, the barrier island is also subject to storm events of differing severity, in which overwash, driven by storm surge, causes barrier erosion and property damage to which the economic and policy agents respond. 
***Please note that this is a preprint and not peer-reviewed. This work is provided by the authors as a means to ensure open access to scholarly work on a non-commercial basis. $* * *$

Like in other simulated markets with complex behavior (Arthur 1994), agents track market indicators (e.g., tourist population, numbers of hotel rooms, room rental price, hotel selling price) and make decisions that maximize their own utility functions. Developer agents decide to build a hotel of a certain size (e.g., number of rooms) if its construction will maximize profit (projected sale price minus cost). Hotel-owning agents bid on hotels for sale if the projected appreciation and revenue of those hotels exceeds the future return of a risk-free investment (Clayton 1997). The offered purchase price for a hotel is found by setting total demand to the number of hotel rooms offered by developer agents. The economic agents are in turn coupled to the physical model by tourist agents seeking to maximize their own utility functions, which depend on a combination of economic and beach parameters (e.g., whether the beach town is a familiar or unfamiliar destination, beach width, total vacation cost per day). Within a model year, tourist agents decide whether or not to vacation, and if so, which beaches to visit; hotel agents adjust room price to maximize revenue; and developer agents decide based on anticipated market behavior whether or not to build new hotels. If damaged in a storm, hotels are rebuilt only if projected revenue minus costs outweigh income for the coming year. This rule means that sections of barrier may be abandoned, and return to an effectively "undeveloped" state. However, if an unprotected barrier segment remains undamaged long enough that developer agents project profits there, then new building initiates.

In the model, this cycle of resort development, coastal defense, and economic collapse continues episodically, predicting an emergent boom-and-bust pattern in the dynamical behavior of a developed barrier island. Moreover, the pattern oscillates in both space and 
***Please note that this is a preprint and not peer-reviewed. This work is provided by the authors as a means to ensure open access to scholarly work on a non-commercial basis. $* * *$

time. The boom phases are associated with thriving tourism and significant investment in mitigation against rising sea level; the bust phases correspond to complete destruction of resort-town infrastructure. Bust cycles are also presaged by exaggerated modifications to barrier geometry - a marked narrowing of barrier width and increase in barrier height, as beach and dune nourishment prevent the island from overwashing as it would under natural circumstances (and thereby maintain its dimensions relative to sea level). An unintended consequence of mitigating against coastal hazard by filtering out the cumulative impacts of small-scale storms is that large storm events overwhelm barrier defenses become even more destructive (Werner and McNamara 2007; McNamara and Werner 2008a; Lazarus 2014). Despite its abstractions, the model showed good agreement when tested against the historical development of Ocean City, Maryland (McNamara and Werner 2008b), and although data records remain either short or sparse, early signs of this long-term behavioral pattern may be appearing at other developed barrier locations along the U.S. East Coast (Pilkey et al. 1998; McNamara and Werner 2008a).

\subsection{CONCLUSIONS}

Recent work by Hapke et al. (2013) investigating historical ( 150 yrs) and recent (25-30 yrs) measurements regional-scale shoreline change along the New England and Mid-Atlantic coasts of the U.S. arrives at a startling conclusion. They find

"a strong correlation... between rates of shoreline change and amount of human development over long time periods and large spatial scales. Even moderate amounts of development are associated with reduced erosion indicating that 
***Please note that this is a preprint and not peer-reviewed. This work is provided by the authors as a means to ensure open access to scholarly work on a non-commercial basis. $* * *$

activities associated with protecting and preserving human infrastructure have a substantial and long-lasting impact. The influence of development also appears to override the geomorphological signal of shoreline behavior, an important consideration for interpretations of investigations of change along developed coasts. Only along sparsely developed coasts does the shoreline respond as expected with respect to the coastal geomorphology" (Hapke et al. 2013, p. 169).

The fact that intensively developed coastlines behave differently in general from natural coastlines is not the surprise: in Japan, in Belgium and the Netherlands, and in regions of Italy and the U.S. (Nagao 1991; Kabat et al. 2009; Nordstrom 1994, 2000), researchers have documented the transition of coastlines from natural systems to "human artifacts that bear little resemblance to the coast that formerly existed" (Nordstrom 2000, p. 16). In this case, the surprise is the effective masking - through sediment diversion, nourishment, and shoreline hardening - of natural geomorphic shoreline-change signals along thousands of kms of coastline. Unlike in the Netherlands, for example, which introduced as part of its national policy framework for coastal defense a comprehensive beach-nourishment program to fix and maintain indefinitely the 1990 position of the Dutch shoreline (Hillen and Roelse 1995), the U.S. Eastern Seaboard reflects no such coordinated policy, planning, or integrated coastal management on any comparable scale. If, as Hapke et al. (2013, p. 169) conclude, "naturally forced variations in rates of shoreline change through time may only be detectable within sparsely developed stretches of coastline," then empirical, analytical, quantitative consideration of humans as principal agents of large-scale coastal geomorphic change 
***Please note that this is a preprint and not peer-reviewed. This work is provided by the authors as a means to ensure open access to scholarly work on a non-commercial basis. $* * *$

(Hooke 1994, 2000, 2012; Haff 2003, 2010, 2012) is a scientific imperative for future coastal sustainability, not just a theoretical exercise (Lazarus et al. 2015).

Whether signals of natural coastal hazards are obscured by gradual, incremental interventions or massive geoengineering works matters to the dynamics of the developed coastal system (Lazarus 2014). Technological interventions, including hazard defenses, buffer human enterprise - the development and infrastructure that supports societal functions and activity - from natural variability, and allow inhospitable places to be not only inhabitable, but comfortable. (Beach nourishment and seawalls aside, imagine South Florida without air conditioning.) However, hazard defenses that evolve incrementally tend to be reactionary for example, raising levee height based on the magnitude of the last storm to overtop them (Werner and McNamara 2007), or expanding the width of a beach enough to lend shorefront protection but not so much that tourists get discouraged by a long trek to the water's edge (Smith et al. 2009). By comparison, massive hazard defenses designed for very long time scales (Kabat et al. 2009) may so overwhelm faster-acting natural processes that the system may appear 'decoupled': defenses over-engineered for short time scales $(<$ decades) may be so effective at preventing damage that the hazard component of the coupled human-natural system shown in Fig. 1 (step 3) is functionally bypassed (Lazarus 2014). However, the unintended consequence of filtering out frequent, minor hazard events that the coupled human-natural system becomes vulnerable to infrequent, major, more destructive events (Werner and McNamara 2007; Lazarus 2014). By extension, once a coupled system has evolved toward a state of low frequency, high magnitude hazard exposure, hazard mitigation requires constant vigilance and maintenance to compensate for 
***Please note that this is a preprint and not peer-reviewed. This work is provided by the authors as a means to ensure open access to scholarly work on a non-commercial basis. $* * *$

increased risk (Lazarus 2014): Consider that in 1953, when a disastrous North Sea winter storm struck the U.K., Dutch, and Belgian coasts, much of the extensive - and essential Dutch flood-defense infrastructure had languished during and after the Second World War (Gerritsen 2005).

For the barriers islands of the U.S. East Coast, given the evident dominance of human interference in patterns of natural coastal sediment flux, the next advances into understanding quantitatively the dynamics of developed coastlines will stem from empirical and analytical investigations of the economic and policy instruments and social processes of decision-making that directly and indirectly affect coastal management, and, in turn, the ways in which developed coastal environments evolve. Direct measurement of anthropogenic controls on storm-driven overwash and washover in developed shorefront zones (Rogers et al. 2015) offers a promising answer to a long-standing data gap (Nordstrom 1994).

Investigations into the intrinsic and external factors, from beach width to tax and insurance subsidies, that influence coastal property values - and the effects those values have on coastal management and policy - comprise another fast-expanding area (Landry et al. 2003; Kriesel and Landry 2004; Bagstad et al. 2007; Bin et al. 2008; Smith et al 2009; Gopalakrishnan et al. 2011; Landry et al. 2011; Jin et al. 2015). Still another underexplored tool for dynamical insight is agent-based modeling with agent behaviors that better capture the psychology of decision-making and adaptive learning, which would represent a departure from agents guided by rule-based optimization of utility functions (Lazarus et al. 2015). Overall, future work on developed coastlines needs to be rich in data analysis of social (including economic) and physical parameters, and engage nonlinear approaches capable of 
***Please note that this is a preprint and not peer-reviewed. This work is provided by the authors as a means to ensure open access to scholarly work on a non-commercial basis. $* * *$

resolving causal drivers, lags, and coupling in complex, dynamical human-landscape systems (Sugihara et al. 2012).

\section{Acknowledgements}

D.E.M. acknowledges funding support from NSF grants (EAR-0952120 and EAR-1053113).

E.D.L. acknowledges funding support from Welsh Government and HEFCW through the Sêr Cymru National Research Network for Low Carbon, Energy and the Environment RESILCOAST Project, and from the UK NERC BLUEcoast project (NE/N015665/2).

\section{REFERENCES}

Arthur WB (1999) Complexity and the economy. Science 284:107-109

Bagstad KJ, Stapleton K, D'Agostino JR (2007) Taxes, subsidies, and insurance as drivers of United States coastal development. Ecol Econ 63:285-298

Bin O, Kruse JB, Landry CE (2008) Flood hazards, insurance rates, and amenities: Evidence from the coastal housing market. J Risk Insur 75:63-82

Butler R (ed) (2006) The tourism area life cycle, vol 1. Channel View Publications, Clevedon Clayton J (1997) Are housing price cycles driven by irrational expectations? J Real Estate Finance Econ 14:341-363

Dean RG, Dalrymple RA (2002) Coastal processes with engineering applications. Cambridge University Press, Cambridge

Dietz T, Ostrom E, Stern PC (2003) The struggle to govern the commons. Science 302:1907-1912.

Dolan R, Lins H (2000) The Outer Banks of North Carolina. U.S. Geological Survey Professional Paper, Report 1177-B (4th printing)

Dunning NP, Beach TP, Luzzadder-Beach S (2012) Kax and kol: Collapse and resilience in lowland Maya civilization. P Natl Acad Sci USA 109:3652-3657 
***Please note that this is a preprint and not peer-reviewed. This work is provided by the authors as a means to ensure open access to scholarly work on a non-commercial basis. $* * *$

Ells K, Murray AB (2012) Long-term, non-local coastline responses to local shoreline stabilization. Geophys Res Lett 39:L19401

FitzGerald DM, Fenster MS, Argow BA, Buynevich IV (2008) Coastal impacts due to sealevel rise. Annu Rev Earth Planet Sci 36:601-647

Freeman DM (1990) Designing local irrigation organization for linking water demand with supply. In: Sampath RK, Young RA (eds) The social, economics and institutional issues on Third World management, Westview Press, Boulder, p 111-140

Gerritsen H (2005) What happened in 1953? The Big Flood in the Netherlands in retrospect. Philos T R Soc A 363:1271-1291

Gopalakrishnan S, Smith MD, Slott JM, Murray AB (2011) The value of disappearing beaches: a hedonic pricing model with endogenous beach width. J Environ Econ Manag 61:297-310

Haff PK (2003) Neogeomorphology, prediction, and the Anthropic landscape. In: Wilcock PR, Iverson RM (eds), Prediction in geomorphology, Geophysical Monograph no 135, American Geophysical Union, Washington, DC, p 15-26

Haff PK (2010) Hillslopes, rivers, plows, and trucks: mass transport on Earth's surface by natural and technological processes. Earth Surf Process Landf 35:1157-1166

Haff PK (2012) Technology and human purpose: the problem of solids transport on the earth's surface. Earth Syst Dyn 3:417-431

Hapke CJ, Kratzmann MG, Himmelstoss EA (2013) Geomorphic and human influence on large-scale coastal change. Geomorphology 199:160-170

Hartman R (1976) The harvesting decision when a standing forest has value. Econ Inq $14: 52-58$

Hardin G (1968) The tragedy of the commons. Science 162:1243-1248

Hillen R, Roelse P (1995) Dynamic preservation of the coastline in the Netherlands. Journal of Coastal Conservation 1:17-28

Hoagland P, Jin D, Kite-Powell HL (2012) The costs of beach replenishment along the U.S. Atlantic Coast. J Coastal Res 28:199-204

Hooke R LeB (1994) On the efficacy of humans as geomorphic agents. GSA Today 4:224 225

Hooke R LeB (2000) On the history of humans as geomorphic agents. Geology 28:843-846 
***Please note that this is a preprint and not peer-reviewed. This work is provided by the authors as a means to ensure open access to scholarly work on a non-commercial basis. $* * *$

Hooke R LeB, Martin-Duque JF, Pedraza J (2012) Land transformation by humans: a review. GSA Today 22:4-10

Jin D, Ashton AD, Hoagland P (2013) Optimal responses to shoreline changes: an integrated economic and geological model with application to curved coasts. Nat Resour Model 26:572-604

Jin D, Hoagland P, Au DK, Qiu J (2015) Shoreline change, seawalls, and coastal property values. Ocean Coast Manage 114:185-193

Kabat P, Fresco LO, Stive MJF et al (2009) Dutch coasts in transition. Nat Geosci 2:450 452

Kriesel W, Landry C (2004) Participation in the National Flood Insurance Program: An empirical analysis for coastal properties. J Risk Insur 71:405-420

Landry CE, Jahan-Parvar MR (2011) Flood insurance coverage in the coastal zone. J Risk Insur 78:361-388

Landry CE, Keeler AG, Kriesel W (2003) An economic evaluation of beach erosion management alternatives. Mar Resour Econ 18:105-127

Lazarus ED (2014) Threshold effects of hazard mitigation in coastal human-environmental systems. Earth Surf Dynam 2:35-45

Lazarus ED, Ellis MA, Murray AB, Hall DM (2015) An evolving research agenda for human-coastal systems. Geomorphology. doi:10.1016/j.geomorph.2015.07.043

Lazarus ED, McNamara DE, Smith MD, Gopalakrishnan S, Murray AB (2011) Emergent behavior in a coupled economic and coastline model for beach nourishment. Nonlinear Proc Geoph 18:989-999

McNamara DE, Keeler A (2013) A coupled physical and economic model of the response of coastal real estate to climate risk. Nature Clim Change 3:559-562

McNamara DE, Werner BT (2008a) Coupled barrier island-resort model: 1 Emergent instabilities induced by strong human-landscape interactions. J Geophys Res Earth Surf 113:F01016. doi:10.1029/2007JF000840

McNamara DE, Werner BT (2008b) Coupled barrier island-resort model: 2 Tests and predictions along Ocean City and Assateague Island National Seashore, Maryland. J Geophys Res Earth Surf 113:F01017. doi:10.1029/2007JF000841

McNamara DE, Gopalakrishnan S, Smith MD, Murray AB (2015) Climate adaptation and policy-induced inflation of coastal property value. PLoS one 10:e0121278. doi:10.1371/journal.pone.0121278 
***Please note that this is a preprint and not peer-reviewed. This work is provided by the authors as a means to ensure open access to scholarly work on a non-commercial basis. $* * *$

McNamara DE, Murray AB, Smith MD (2011) Coastal sustainability depends on how economic and coastline responses to climate change affect each other. Geophys Res Lett 38:L07401. doi:10.1029/2011GL047207

Mileti D (1999) Disasters by design, National Academy Press, Washington, DC

Murray AB, Ashton AD (2013) Instability and finite-amplitude self-organization of largescale coastline shapes. Philos T R Soc A 371:20120363

Murray AB, Gopalakrishnan S, McNamara DE, Smith MD (2013) Progress in coupling models of human and coastal landscape change. Comput Geosci 53:30-38

Nagao Y (1991) Coastlines of Japan. American Society of Civil Engineers, New York

NOAA (National Oceanic and Atmospheric Administration) (2006) Beach nourishment: A guide for local government officials. NOAA Coastal Services Center. Available via https://coast.noaa.gov/archived/beachnourishment/html/human/law/index.htm. Accessed 5 Janurary 2015

NOAA (2013) U.S. Population living at the coast. Available via http://stateofthecoast.noaa.gov/population/welcome.html. Accessed 5 January 2015

Nordstrom KF (1994) Beaches and dunes of human-altered coasts. Prog Phys Geog 18:497_ 516

Nordstrom KF (2000) Beaches and dunes of developed coasts. Cambridge University Press, Cambridge

National Research Council (NRC) (2014) Reducing coastal risk on the East and Gulf Coasts. National Academies Press, Washington, DC

Ostrom E, Gardner R (1993) Coping with asymmetries in the commons: self-governing irrigation systems can work. J Econ Perspect 7:93-112

Ostrom E, Burger J, Field CB, Norgaard RB, Policansky D (1999) Revisiting the commons: local lessons, global challenges. Science 284:278-282

Phillips L (2012) Sea versus senators. Nature 486:450

Pilkey OH, Dixon KL (1996) The Corps and the shore. Island Press, Washington, DC

Pilkey OH, Wright HL III (1988) Seawalls versus beaches. J Coast Res SI 4:41-64.

Pilkey OH et al (1998) The North Carolina shore and its barrier islands. Duke University Press, Durham 
***Please note that this is a preprint and not peer-reviewed. This work is provided by the authors as a means to ensure open access to scholarly work on a non-commercial basis. $* * *$

PSDS (Program for the Study of Developed Shorelines) (2015) Beach nourishment database. Available via http://psds.wcu.edu/projects-research/beach-nourishment/. Accessed 5 January 2015

Rogers LJ, Moore LJ, Goldstein EB, Hein CJ, Lorenzo-Trueba J, Ashton AD (2015) Anthropogenic controls on overwash deposition: Evidence and consequences. J Geophys Res Earth Surf doi:10.1002/2015JF003634

Slott JM, Murray AB, Ashton AD (2010) Large-scale responses of complex-shaped coastlines to local shoreline stabilization and climate change. J Geophys Res Earth Surf 115:F03033. doi:10.1029/2009JF001486

Slott JM, Smith MD, Murray AB (2008) Synergies between adjacent beach-nourishing communities in a morpho-economic coupled coastline model. Coast Manage 36:374-391

Smith K (2013) Environmental hazards: Assessing risk and reducing disaster, 6th edn. Routledge, London

Smith MD, Slott JM, McNamara DE, Murray AB (2009) Beach nourishment as a dynamic capital accumulation problem. J Environ Econ Manag 58:58-71

Stone K, Kaufman B (1988) Sand rights: a legal system to protect the 'shores of the sea'. Shore and Beach 56:7-14

Stutz ML, Pilkey OH (2011) Open-ocean barrier islands: global influence of climatic, oceanographic, and depositional settings. J Coastal Res 27:207-222

Sugihara G, May R, Ye H et al (2012) Detecting causality in complex ecosystems. Science 338:496-500

Trembanis AC, Pilkey OH, Valverde HR (1999) Comparison of beach nourishment along the US Atlantic, Great Lakes, Gulf of Mexico, and New England shorelines. Coast Manage 27:329-340

Turner BL II, Sabloff JA (2012) Classic Period collapse of the Central Maya Lowlands: Insights about human-environment relationships for sustainability. P Natl Acad Sci USA 109:13908-13914

Valverde HR, Trembanis AC, Pilkey OH (1999) Summary of beach nourishment episodes on the US east coast barrier islands. J Coast Res 15:1100-1118

Werner BT, McNamara DE (2007) Dynamics of coupled human-landscape systems. Geomorphology 91:393-407 